\title{
Analysis of the Influence of Lunar Cycle on the Frequency of Spontaneous Deliveries: A Single-centre Retrospective Study. Laganà AS, ${ }^{1}$ Burgio MA, Retto $G,{ }^{1}$ Pizzo $A,{ }^{1}$ Sturlese $E,{ }^{1}$ Granese $R,{ }^{1}$ Chiofalo $B,{ }^{1}$ Ciacimino $\mathrm{L}^{1}{ }^{1}$ Triolo $\mathrm{O}^{1}$
}

${ }^{1}$ Department of Pediatric, Gynecological, Microbiological and Biomedical Sciences

University of Messina, Via C. Valeria 1, 98125 Messina - Italy.

${ }^{2}$ Department of Gynecology and Obstetrics

Palermo Civic Hospital and National Center of Clinical Excellence (ARNAS Di Cristina-Benfratelli) Palermo, Italy.

\section{Corresponding Author}

Antonio Simone Laganà

Department of Pediatric, Gynecological, Microbiological and Biomedical Sciences

University of Messina, Via C. Valeria 1, 98125 Messina - Italy.

Email: antlagana@unime.it

\section{Citation}

Laganà AS, Burgio MA, Retto G, Pizzo A, Sturlese E, Granese R et al. Analysis of the Influence Of Lunar Cycle on The Frequency Of Spontaneous Deliveries: A Single-centre Retrospective Study. Kathmandu Univ Med J 2014;48(4):233-7.

\section{ABSTRACT}

\section{Background}

Man, since ancient times, has been convinced of, and has researched scientific evidence that the barometric and gravitational forces play an important role in structural and biological variation of the planets, influencing the various forms of life. In particular, the synergistic relationships between variations in atmospheric pressure and gravitational forces on human gestation period have been the subject of rigorous observations and statistical calculations, which have not led to a universal conclusion in literature.

\section{Objectives}

The aim of our work was to check whether there is a higher incidence of spontaneous deliveries, during the periods of full Moon than during the other phases of the Moon.

\section{Methods}

We performed a retrospective analysis of 327 non-induced vaginal deliveries in a year, divided by month. We subsequently analyzed the incidence of these deliveries during periods of full Moon Vs other lunar phases.

\section{Results}

We evidenced a statistically significant difference between the annual total spontaneous deliveries happened in full Moon periods Vs all other Moon phases $(T=2,3946 ; p=0,0256)$. However, we reported a discordant trend of deliveries in full Moon period, depending on each considered month.

\section{Conclusion}

Since these differences were found both in increase and decrease, it is unacceptable the assumption of a linear correlation between periods of full Moon and increased frequency of spontaneous deliveries. For this reason, our data allow us to conclude that there is no need to increase the number of doctors and midwives in obstetric units during these periods.

\section{KEY WORDS}

Biological clock, delivery, lunar cycle, pregnancy 


\section{INTRODUCTION}

Man, since ancient times, has been convinced of and has researched scientific evidence that the barometric and gravitational forces play an important role in structural and biological variation of the planets, influencing the various forms of life. During the last century there has been scientific evidence demonstrating that natural environmental forces affect physiological and psychological processes of human species. The theories about life cycles have given impetus to circadian studies of correlation between man and the environment. The circadian clock is a self-contained oscillator on a period of $24 \mathrm{~h}$ that controls many physiological and behavioral systems, optimizing and synchronizing the biological benefits to changing environmental conditions. ${ }^{1}$ These circadian rhythms seem to be generated by the periodic activation of the transcription of a set of genes called "clock". In line with this theory, studies on Drosophila have demonstrated the existence of a circadian biological clock and have also identified the regulatory genes: timeless (tim), clock (clk), cycle (cyc), doubletime (dbt), cryptochrome (cry) and vrille (vri). ${ }^{2-5}$ Alterations in these genes affect circadian rhythm by altering the biological functions linked to it. ${ }^{6}$ Many aspects of human physiology as sleep-wake rhythm, body temperature, alertness and performance, blood levels of melatonin and cortisol, are governed by a circadian oscillator, the suprachiasmatic nucleus, located in the anterior part of the hypothalamus, in order to ensure the programming of the adaptive response to external changes. In particular, the day/night cycle is transposed as an input from the retinal photoreceptors, which transmit that information to the central nervous system (CNS), which in turn regulates the phases of sleep and watch. In addition, exposure to light at night suppresses the synthesis of melatonin by the pineal gland through a complex signaling system of CNS, which involves the para ventricular nucleus and the superior cervical ganglion. ${ }^{7}$ As far as human reproduction is concerned, Sarkar and Biswas have noted that the women's vaginal $\mathrm{pH}$ during the ovulatory phase, ${ }^{8}$ coinciding with the full Moon, was alkaline ( $\mathrm{pH} 8.7 \pm 0.4)$, while that of women who had ovulated, during the three previous days, was slightly acid ( $\mathrm{pH} 6.26 .4 \pm 0.5$,); the body temperature was increased $\left(+0.5^{\circ} \mathrm{F}\right)$ in women who had ovulated in coincidence with the full Moon; finally they have associated the alkaline environment and the basal body temperature with the conception of male infants.

In addition, the synergistic relationships between changes of atmospheric pressure and gravitational forces on the human gestation period were subject to rigorous observations and statistical calculations. As evidenced by Hajek et al. ${ }^{9}$, the primary determinants of annual seasonal conception rate rhythms, for the human as for other mammals, are day length and temperature. Furthermore, the phase reversal of the annual rhythm over the last few generations in most highly industrialized populations makes it clear that the transduction of information from changes in day length and temperature into changes in human behavior and physiology will generate compelling questions for further exploration. ${ }^{10}$

Considering the conflicting data on this topic, the aim of the current work was to check whether there is a higher incidence of spontaneous deliveries, during the periods of full Moon than during the other phases of the Moon.

\section{Phases of the Moon}

The movement of the Moon around the Earth generates 2 different periods: the "Sidereal month" and the "Synodic month". "Sidereal month" is considered as the time it takes the Moon to make one complete revolution around the Earth, to return in the same spot, in reference to the stars (sidereal space); "Synodic month" is indicated as the time it takes the Moon to make one complete revolution around the Earth, to return to the same point in relation to the Sun. The time it takes the Moon to make one lap around the Earth, considering the sidereal space, is about 27.3 days. Meanwhile the Earth rotating around the Sun at a speed of 0.985 degrees per day, in 27.3 days is moved to 26.91 degrees, whereby the Moon stays later, relative to the Sun, 2.043 days; the Synodic month is about 29.5 days. Astrophysicists have calculated the Synodic month exactly 29 days, 12 hours, 44 minutes, 2.9 seconds. The time that elapses between two full Moons equals the Synodic month, so 29.5 days. (Fig 1 ).

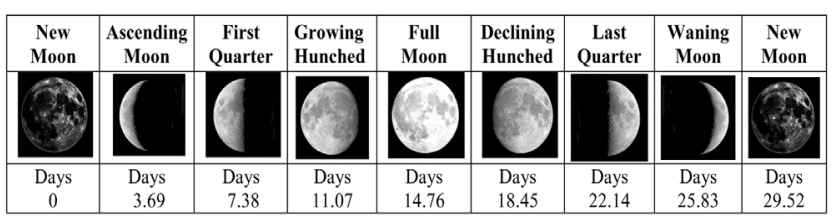

Figure 1. The phases of the Moon (Synodic month).

\section{METHODS}

This single-center retrospective study was performed at the Department of Obstetrics and Gynecology of the University Hospital "G. Martino" (Messina, Italy). All the designs, analysis, interpretation of data, drafting and revisions conform the Strengthening the Reporting of Observational Studies in Epidemiology (STROBE), ${ }^{11}$ drawn by the Enhancing the Quality and Transparency Of health Research (EQUATOR) network (http://www.equatornetwork.org/), the Committee on Publication Ethics (COPE) guidelines and was approved by the Institutional Review Board (IRB) of the university hospital in which it was performed. Each enrolled patient was informed in a comprehensive and complete way about investigations that we were going to perform, and signed an informed consent for the data collection for research purposes.

We performed an analysis on 382 spontaneous deliveries which occurred from $1^{\text {st }}$ January to $31^{\text {th }}$ December 2011, sorted by month. In Tab. 1 we reported the total amount of deliveries each month, both induced or not: subsequently, 
Table 1. Analysis of total monthly vaginal deliveries, both noninduced and induced.

\begin{tabular}{|lccc|}
\hline YEAR 2011 & \multicolumn{3}{c|}{ Vaginal deliveries } \\
\hline January & Total & Non-induced & Induced \\
\hline February & 34 & 30 & 4 \\
\hline March & 33 & 26 & 7 \\
\hline April & 31 & 30 & 1 \\
\hline May & 35 & 31 & 4 \\
\hline June & 19 & 14 & 5 \\
\hline July & 25 & 21 & 4 \\
\hline August & 32 & 27 & 5 \\
\hline September & 33 & 30 & 3 \\
\hline October & 23 & 18 & 5 \\
\hline November & 46 & 37 & 9 \\
\hline December & 35 & 29 & 6 \\
\hline TOTALS & 36 & 34 & 2 \\
\hline
\end{tabular}

Table 2. Analysis of deliveries falling during full moon Vs. other phases of the moon.

\begin{tabular}{|lcccc|}
\hline $\begin{array}{l}\text { YEAR 2011 } \\
\text { Month } \\
\text { (Full Moon Day) }\end{array}$ & $\begin{array}{c}\text { Non-induced vaginal deliveries } \\
\text { Other } \\
\text { days }\end{array}$ & $\begin{array}{c}\text { Full Moon } \\
(-1)\end{array}$ & $\begin{array}{c}\text { Full } \\
\text { Noon }\end{array}$ & $\begin{array}{c}\text { Full Moon } \\
(+1)\end{array}$ \\
\hline January (19 Wed) & 28 & N & N & N \\
\hline February (18 Fri) & 21 & 2 & 0 & 2 \\
\hline March (19 Sat) & 28 & 1 & 1 & 2 \\
\hline April (18 Mon) & 30 & 1 & 1 & 0 \\
\hline May (17 Tue) & 10 & 1 & 2 & 0 \\
\hline June (15 Wed) & 16 & 2 & 2 & 1 \\
\hline July (15 Fri) & 22 & 2 & 1 & 2 \\
\hline August (13 Sat) & 28 & 1 & 0 & 1 \\
\hline September (12 Mon) & 14 & 2 & 1 & 1 \\
\hline October (12 Wed) & 33 & 3 & 1 & 0 \\
\hline November (10 Thu) & 25 & 1 & 1 & 2 \\
\hline December (Sat 10) & 31 & 1 & 0 & 2 \\
\hline TOTALS & 286 & 17 & 10 & 14 \\
\hline
\end{tabular}

we excluded all induced labors/deliveries from the current study. Full Moon days sorted by month were established. We built a database with deliveries ordered for each day of the month, in order to consider if they occurred in full Moon periods or not. We considered as full Moon period the day before, the day of full Moon, and the day after ("full Moon windows"). Since all the patients were retrospectively enrolled in a single center, we can assume no influence of the equatorial line distance on the analyzed parameters. In Tab. 2 we reported deliveries occurred in full Moon periods Vs all other Moon phases, sorted by months. We performed Student's T test to compare means between the two groups. As shown in Tab. 3, we calculated deliveries/ day means for full Moon periods Vs all other Moon phases.
Table 3. Analysis of non-induced vaginal deliveries/day means for full moon periods Vs. all other phases of the moon.

\begin{tabular}{|lcccc|}
\hline YEAR 2011 & $\begin{array}{c}\text { Non-induced vaginal } \\
\text { deliveries } \\
\text { (Other moon periods) } \\
\text { /day }\end{array}$ & $\begin{array}{c}\text { Non-induced vagi- } \\
\text { nal deliveries } \\
\text { (Full moon periods) } \\
\text { /day }\end{array}$ \\
\hline Months & N & mean & N & mean \\
\hline January (19 Wed) & 28 & 0,90 & 2 & 0,67 \\
\hline February (18 Fri) & 21 & 0,75 & 5 & 1,67 \\
\hline March (19 Sat) & 28 & 0,90 & 2 & 0,67 \\
\hline April (18 Mon) & 30 & 1,00 & 1 & 0,33 \\
\hline May (17 Tue) & 10 & 0,32 & 4 & 1,33 \\
\hline June (15 Wed) & 16 & 0,53 & 5 & 1,67 \\
\hline July (15 Fri) & 22 & 0,71 & 5 & 1,67 \\
\hline August (13 Sat) & 28 & 0,90 & 2 & 0,67 \\
\hline September (12 Mon) & 14 & 0,47 & 4 & 1,33 \\
\hline October (12 Wed) & 33 & 1,06 & 4 & 1,33 \\
\hline November (10 Thu) & 25 & 0,83 & 4 & 1,33 \\
\hline December (Sat 10) & 31 & 1,00 & 3 & 1,00 \\
\hline
\end{tabular}

\section{RESULTS}

Means analysis (Tab. 3), using Student's T test, evidenced a statistically significant difference between the annual total spontaneous deliveries happened in full Moon periods Vs all other Moon phases ( $T=2,3946 ; p=0,0256)$. However, we reported a discordant trend of deliveries in full Moon periods, depending on considered month: we evidenced an increase in February, May, June, July, September, October and November, while a decrease in January, March, April and August, and finally no difference in December (Fig. 2).

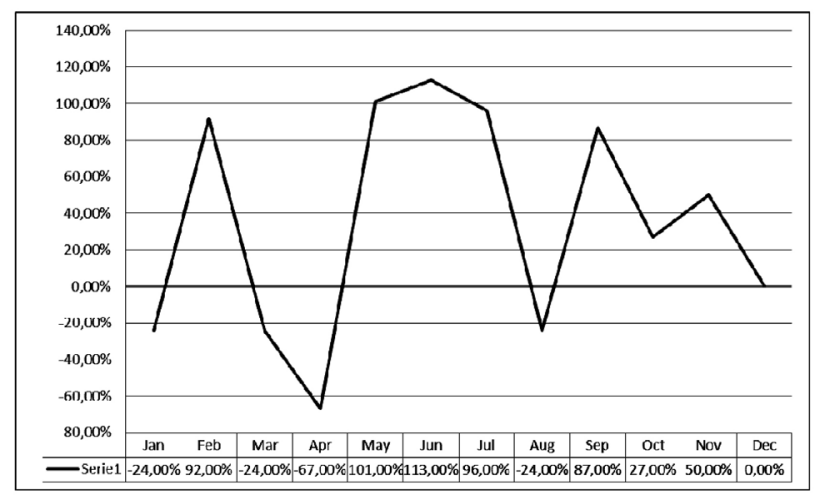

Figure 2. Monthly trend analysis of the frequency of spontaneous deliveries in coincidence full Moon phases.

\section{DISCUSSION}

Long-term secular trends in birth rates and annual seasonal rhythms in conceptions are well known from numerous prior reports, if not perhaps fully understood. There is a persistent myth in several societies about the influence of lunar cycles on deliveries. Even nowadays, many delivery nurses attest that the number of women going into labour and giving birth is higher during the full Moon. For example, 
Danzl mention that in $1987,1280 \%$ of nurses and $64 \%$ of doctors believed that there was an impact of the Moon, this phenomenon has been termed the full Moon effect, from Schnurman. ${ }^{13}$

A study of Criss and Marcum, ${ }^{14}$ performed in 1968 on a sample of 140000 deliveries with alive babies, found few indications of the influence of the Moon phase on childbirth, but reported a correlation between light and menstrual regularity, and that the waning Moon period negatively affects the ovulation. In addition, Wake et al. ${ }^{15}$ on a sample of 1007 births, have observed a significant increase of births when the gravitational influence of the Moon on Earth was less than 31.5 Newton. Partially confirming these latest findings, on a very large study cohort (5927978 births), other Authors showed a higher incidence of births in coincidence of the period between the last quarter of the Moon and the new Moon. ${ }^{16}$ In addition, by retrospective analysis of 1248 spontaneous deliveries in three years (36 lunar months), performed by Ghiandoni et al., ${ }^{17,18}$ it was found that the effect of the phases of the Moon can be considered significant for multiparous and plurigravide women, in which the average day of delivery coincides with the first or the second day after the full Moon; However these data are not sufficient to guarantee a forecast of the days with the higher incidence of deliveries. On the other hand, a study by Abell and Greenspan, ${ }^{19}$ on 11691 deliveries in 51 lunar cycles, shows no correlation between birth rate and the phases of the Moon. Data provided by other Authors, ${ }^{20}$ with a cohort study of the same amount, has not recorded statistically significant differences in the frequency of deliveries during the various phases of the lunar cycle, regardless of the type of delivery. Data provided by Joshi et al., ${ }^{21}$ Periti et al. ${ }^{22}$ and Romero Martinez et al. ${ }^{23}$ seems to be conclusive: they showed that there was no statistically significant difference between the frequency of the deliveries during full Moon days compared to other days, concluding that the analysis of the evidence provided does not support the theory which states that the full Moon phase is related to an increase in the frequency of the deliveries. Other studies have investigated the influence that the phases of the Moon may have on the complications of childbirth and neonatal outcomes; in particular, data provided by Arliss et al. ${ }^{24}$ and Staboulidou et al. ${ }^{25}$ have not found any influence of the lunar cycle on birth and neonatal complications. Consideration of the influence of the Moon on the tides led, over the centuries, to believe that it may have an effect on the pressure of the amniotic fluid of pregnant women, and that, consequently, a sudden change of pressure could cause the premature rupture of membranes (PROM), thereby inducing labor. The study of Lentz et al., ${ }^{26}$ investigated the synergistic relationship between barometric pressure and gravitational forces in relation to the physiology of pregnancy, concluding that neither the size nor the barometric pressure gradient have a significant effect on human gestation and that gravitational influences of the new and full Moons have had no impact on the rate of deliveries. The PROM does not seem to be affected by the phases of the Moon and the barometric changes, but most commonly appears during the night hours, specifically between 10:00 PM and 06:00 AM..$^{27}$

We reported a statistically significant difference between the annual total spontaneous deliveries happened in full Moon periods Vs all other Moon phases. However, we evidenced a discordant trend of deliveries in full Moon period, depending on considered month. Our data do not find agreement with the weekly rhythm, nor with the annual rhythm or with the Synodic lunar month as defined in the study of Guillon et al., ${ }^{16}$ considered the largest sample size for study (5927978 cases) and span (6 years); on the contrary, our conclusions agree with those given by numerous other studies found in literature. ${ }^{19-23}$

\section{CONCLUSION}

Since our data analysis, it is unacceptable the assumption of a linear correlation between periods of full Moon and increased frequency of spontaneous deliveries. For this reason, our data allow us to conclude that there is no need to increase the number of doctors and midwives in obstetric units during these periods.

\section{REFERENCES}

1. Albrecht U. Invited review: regulation of mammalian circadian clock genes. J Appl Physiol. 2002;92(3):1348-55.

2. Allada R, White NE, So WV, Hall JC, Rosbash M. A mutant Drosophila homolog of mammalian Clock disrupts circadian rhythms and transcription of period and timeless. Cell. 1998;93(5):791-804.

3. Blau J, Young MW. Cycling vrille expression is required for a functional Drosophila clock. Cell. 1999;99(6):661-71

4. Kloss B, Price JL, Saez L, Blau J, Rothenfluh A, Wesley CS, Young MW. The Drosophila clock gene double-time encodes a protein closely related to human casein kinase lepsilon. Cell. 1998;94(1):97-107.

5. Myers MP, Wager-Smith K, Wesley CS, Young MW, Sehgal A. Positional cloning and sequence analysis of the Drosophila clock gene, timeless. Science. 1995;270(5237):805-8.
6. Rutila JE, Suri V, Le M, So WV, Rosbash M, Hall JC. CYCLE is a second bHLH-PAS clock protein essential for circadian rhythmicity and transcription of Drosophila period and timeless. Cell. 1998;93(5): 805-14.

7. Jung CM, Khalsa SB, Scheer FA, Cajochen C, Lockley SW, Czeisler CA Wright KP Jr. Acute effects of bright light exposure on cortisol levels. $J$ Biol Rhythms. 2010;25(3):208-16.

8. Sarkar M, Biswas NM. Influence of Moonlight on the birth of male and female babies. Nepal Med Coll J. 2005;7(1):62-4.

9. Hajek ER, Gutiérrez JR, Espinosa G. Seasonality of conception in human populations in Chile. Int J Biometeorol. 1981;25(4):281-91.

10. Boklage CE. Effects of a behavioural rhythm on conception probability and pregnancy outcome. Hum Reprod. 1996;11(10):2276-84. 
11. Von Elm E, Altman DG, Egger M, Pocock SJ, Gøtzsche PC, Vandenbroucke JP. STROBE Initiative. The Strengthening the Reporting of Observational Studies in Epidemiology (STROBE) statement: guidelines for reporting observational studies. Lancet. 2007;370(9596):1453-7.

12. Danzl DF. Lunacy. J Emerg Med. 1987;5(2):91-5.

13. Schnurman AG. The effect of the moon on childbirth. Va Med Mon (1918). 1949;76(2):78.

14. Criss TB, Marcum JP. A lunar effect on fertility. Soc Biol. 1981;28(12):75-80

15. Wake R, Misugi T, Shimada K, Yoshiyama M. The effect of the gravitation of the Moon on frequency of births. Environ Health Insights. 2010;4:65-9.

16. Guillon P, Guillon D, Lansac J, Soutoul JH, Bertrand P, Hornecker JP. Births, fertility, rhythms and lunar cycle. A statistical study of 5,927,978 births. J Gynecol Obstet Biol Reprod (Paris). 1986;15(3):265-71.

17. Ghiandoni G, Seclì R, Rocchi MB, Ugolini G. Does lunar position influence the time of delivery? A statistical analysis. Eur J Obstet Gynecol Reprod Biol. 1998;77(1):47-50.

18. Ghiandoni G, Seclì R, Rocchi MB, Ugolini G. Incidence of lunar position in the distribution of deliveries. A statistical analysis. Minerva Ginecol. 1997;49(3):91-4.

19. Abell GO, Greenspan B. Human births and the phase of the Moon. N Engl J Med. 1979;300(2):96.
20. Bharati S, Sarkar M, Haldar PS, Jana S, Mandal S. The effect of the lunar cycle on frequency of births: a retrospective observational study in Indian population. Indian J Public Health. 2012;56(2):152-4.

21. Joshi R, Bharadwaj A, Gallousis S, Matthews R. Labor ward workload waxes and wanes with the lunar cycle, myth or reality? Prim Care Update Ob Gyns. 1998;5(4):184.

22. Periti E, Biagiotti R. Lunar phases and incidence of spontaneous deliveries. Our experience. Minerva Ginecol. 1994;46(7-8):429-33.

23. Romero Martínez J, Guerrero Guijo I, Artura Serrano A. The Moon and delivery. Rev Enferm. 2004;27(11):7-9, 11-2.

24. Arliss JM, Kaplan EN, Galvin SL. The effect of the lunar cycle on frequency of births and birth complications. Am J Obstet Gynecol. 2005;192(5):1462-4.

25. Staboulidou I, Soergel P, Vaske B, Hillemanns P. The influence of lunar cycle on frequency of birth, birth complications, neonatal outcome and the gender: a retrospective analysis. Acta Obstet Gynecol Scand. 2008;87(8):875-9.

26. Lentz SK. Changes in Human Gestation Period due to Variations in External Environmental Forces. Pacific Journal of Science and Technology. 2005;6(2):149-169.

27. Trap R, Helm P, Lidegaard O, Helm E. Premature rupture of the fetal membranes, the phases of the Moon and barometer readings. Gynecol Obstet Invest. 1989;28(1):14-8. 